36. Krause C. F. T. Handbuch der menschlichen Anatomie. Hannover. 1879. Dritte, neu bearbeitete Auflage von W. Krause. - 360-361.

37. Kriickmann E. Syphilis der Regenbogenhaut. Breslau. 1906. - 3,4.

38. Oxford advanced learner's Dictionary of Current English. Cornelsen, 2010. - 1714, 1724.

39. Roche Lexikon. 5 Auflage Medizin Urban Fischer.2003. 946.

40. Sondermann R. Beitrag zur Kenntnis der Irisentwicklung // Graefes Arch. - 133. - 1934. - 67-74.

41. Schreck E. Lehrbuch und Atlas der Augenheilkunde. G. Fischer Verlag. Stuttgart, N.York. 1980. - 287.

42. Spalton D. J. Atlas of clinical Ophthalmology, second edition. 1993. - 9.2-9.3.
43. Spalton D. J. Atlas der Augenkrandkeiten. 2.Auflage. Stuttgardt, New York. Thieme. 1996. - 206-207.

44. Tetzer M. Compendium der Augenheilkunde. Wien. 1870. - 140-144.

45. Trost H. Taxonomie und Ontologie WS. 2010/201. - 1-22.

46. Weber H. E., Hildebrandt G. F. Handbuch der Anatomie des Menschlichen Auges. Brandenburg. 1832. - 79.

47. Welhagen K. Der Augenarzt. Band 1.VEB GeorgTieme. Leipzig. 1958. - 47, 313.

48. Wolf rum M. Uber den Bau der Irisvorderflache des menschlichen Auges mit vergleichend anatomischen Bemerkungen // Arch. Ophthal. - 1922. - 108.

Поступила 16.01.2012

Рецензент д. м. н. Э. В. Мальцев

\title{
SOME PECULIARITIES OF THE ANATOMICAL TERMINOLOGY OF THE ANTERIOR SURFACE AND PUPIL EDGE OF THE IRIDESCENT MEMBRANE OF MAN.
}

\section{Zhuravlev A. A.}

Dresden, Germany

The clinical model of the iridescent membrane with the terminological isolation of the anterior and posterior front pupil edge for more exact expression of the peculiarities of its embryogenesis, morphology and function is proposed. The used term «torus of the iridescent membrane» better corresponds to the requirements of the anatomical nomenclature than known synonyms (circle, zone, region, tag of the iris, band-collar, collar, frill, collarette, Iriskrause, Krauze circle), which allows to avoid contradictions and difficulties for translation because of the intercultural and historical differences

\section{Глазами пациента}

\section{ЧУЖОЙ БЕДЫ НЕ БЫВАЕТ, ИЛИ ТРИ МОНОЛОГА О БЛАГОРОДНОЙ РАБОТЕ}

\section{Г. А. Эльчиев, член Союза журналистов России, г. Севастополь}

Я уселся в указанное мне кресло для консультативного осмотра главным врачом клиники Института глазных болезней и тканевой терапии им. Академика В. П. Филатова, доктором медицинских наук В. А. Науменко.

Редкий случай, когда его мобильный телефон подал свой голос в перерыве между осмотрами пациентов. Увидев высветившийся номер, Владимир Александрович, извинившись передо мною, ответил абоненту. Он сказал, что выезжать в командировку надо уже завтра утром; что дети, живущие в приюте одного из монастырей Черновицкой области, ждут наших врачей; что руководит организацией подготовки поездки Тарас Богданович Кустрин, номер его мобильного такой-то; что в группе вакансия и он, Владимир Александрович, просит своего абонента закрыть образовавшуюся брешь.

Любознательность журналиста не позволила мне равнодушно пройти мимо этого факта.
Из дальнейшего разговора, состоявшегося уже в кабинете В. А. Науменко, я уяснил, что в недельную командировку от Института им. В. П. Филатова уезжает группа из пяти врачей. Старшим назначен Т. Б. Кустрин. А всего в медицинском «десанте» в Черновицкую область от Одессы участвует 18 человек, в том числе терапевты, кардиологи, хирург, гастроэндокринолог и другие специалисты из медицинских учреждений города.

Это уже вторая (первая была в 2009 году) поездка с участием врачей Института, в Банчевский Свято-Вознесенский мужской монастырь, настоятель которого отец Михаил, ставший в последнее время известным всей Украине. Почему именно этот монастырь? Дело в том, что именно здесь отец Михаил организовал приют (по нашим сведениям - единственный на Украине) для ВИЧ-

(c) Г. А. Эльчиев, 2012 
инфицированных детей. В этом приюте живут 20 детей из Одесского детского дома.

О том, что В. А. Науменко курировал и первую, и вторую поездки в Свято-Вознесенский монастырь, впрочем, как и множество других подобных акций, он умолчал. Деликатно и дипломатично ушел в глухую защиту от попытки взять у него интервью, сославшись на то, что предпочитает делать, а не говорить. «Если бы вы знали, Геннадий Андреевич, какую я сейчас выполнил операцию!» Глаза Владимира Александровича светились радостью и торжеством мастера, ювелирно и красиво исполнившего свою работу. Да так, что даже ему, с повышенным чувством самокритичности и неуспокоенности, даже ему самому понравилось.

А чтобы загладить неловкость своего отказа в интервью, он назвал трех специалистов, которые, по его мнению, не только хорошо делают свое дело, но и могут рассказать об этом.

К ним я и отправился.

1. Чужих детей не бывает, или монолог первый

О результатах благотворительной командировки специалистов Института им. В. П. Филатова рассказывает старший группы врачей-офтальмологов Кустрин Тарас Богданович, врач отделения лазерной микрохирургии глаза.

Специалисты института ездили в Черновицкую область, где проводились профосмотры служителей как Свято-Вознесенского мужского монастыря, расположенного в селе Банчены Герцаевского района, так и Боянского женского монастыря, что в Новоселицком районе, а также детей детского приюта. В этой благотворительной акции приняли участие: д-р мед. наук Бушуева Наталья Николаевна, канд. мед. наук Суходоева Лина Александровна, врачи Грубник Наталья Павловна, Курилюк Андрей Николаевич и я.

У нас на приеме было 200 взрослых и 40 детей, в том числе 20 ВИЧ-инфицированных детей, которые попали в приют монастыря из Одесского детского дома. У взрослых - в основном, это монахи и монахини, были выявлены такие заболевания, как катаракта, глаукома, диабетическая ретинопатия, возрастная дегенерация макулы, синдром «сухого» глаза. Во всех случаях было назначено и расписано лечение, результаты которого мы намереваемся проконтролировать в свой следующий приезд. В более тяжелых случаях мы рекомендовали визит в Институт им. В. П. Филатова для дообследования и определения тактики лечения таким пациентам.

В таком плотном рабочем ритме прошла у нас вся неделя. Только однажды после сокращенного рабочего дня мы позволили себе ознакомительную поездку в Боянский женский монастырь, где с большим интересом и почтением осмотрели мирроточащую «плачущую» икону Божией Матери.
Был выезд в детский приют, расположенный в селе Молница, где мы познакомились с детьми, пообщались, вручили приготовленные для них подарки.

А в воскресное утро, после благословения отца Михаила, мы отправились в обратную дорогу.

Отец Михаил заслуживает особого почтения и внимания к своей личности. Он не просто настоятель Свято-Вознесенского мужского монастыря. Он совершил гражданский подвиг, взяв под свою защиту и опеку 250 детей, таким образом, приняв на себя ответственность за их судьбы. Практически, почти у всех детей, включая ВИЧ-инфицированных, его фамилия. Отцу Михаилу в этом благородном деле помогают монахини, закрепленные за каждой комнатой, в которых живут дети.

Итогом поездки я доволен. Мы увидели красоту края, которая нас всех очень впечатлила, невзирая на осень. Чистый воздух, а пейзажи - эти леса, эти озера! Но особенно меня поразил подвижнический образ отца Михаила, для которого не только беды чужой, но и детей чужих не бывает.

\section{2. Пророчество бабушки, или монолог второй}

Рассказывает Андрей Ростиславович Король, заведуюший отделением лазерной микрохирургии глаза Института глазных болезней и тканевой терапии им. академика В. П. Филатова, кандидат медицинских наук.

Родился я в городе Никополь Днепропетровской области. Основную часть своего детства провел в Киеве, хотя пришлось пожить и в Нальчике на Северном Кавказе, и в Невеле Псковской области и в Краснодарском крае. В Киеве окончил медицинский университет им. А. А. Богомольца, и в 2000 году начал профессиональную деятельность в интернатуре Центра микрохирургии глаза.

В медицину потянуло с раннего детства, потому что меня воспитывали как будущего врача. С детских лет запомнились слова бабушки: «Не ковыряй пальчиком в носу, ты же будущий доктор!». Поэтому я не мог вырасти никем другим, чтобы не огорчать любимую бабушку.

Почему офтальмологом? Моя тетя офтальмолог, и однажды я, побывав с нею за границей, увидел, как работают офтальмологи в Германии. Меня это заинтересовало, потом я наблюдал работу офтальмологов Украины. На пятом курсе университета мне посчастливилось познакомиться с Натальей Владимировной Пасечниковой, ставшей моим учителем. Когда я закончил шестой курс, она пригласила меня в своё отделение в интернатуру, а затем - на работу врачом-ординатором.

В Одессу на постоянное жительство и работу в Институте глазных болезней и тканевой терапии им. академика В. П. Филатова в 2004 году мы приехали вместе: Наталья Владимировна Пасечникова, Владимир Александрович Науменко, Александра 
Владимировна Зборовская и я. В этом же году я защитил кандидатскую диссертацию по лазерным методам лечения глаза и был принят в штат лаборатории лазерной офтальмохирургии, которую с 1963 года, с момента её образования, возглавляет профессор, д-р мед. наук Л. А. Линник. Бессменный руководитель отдела, Леонид Андреевич не только впервые в Советском Союзе, но и впервые в мире выполнил лазерную коагуляцию сетчатки у человека. Именно с 1963 года ведется разработка новых лазерных методик лечения людей с заболеваниями глаза. Всё это время мы, ученики и последователи Леонида Андреевича, стараемся развивать и совершенствовать это направление.

В 2008 году лаборатория была преобразована в отдел по изучению влияния лазерного излучения на структуры глаза, при котором открылось отделение лазерной микрохирургии глаза, возглавить которое доверили мне.

В отделе семь кандидатов медицинских наук, всего в коллективе 20 человек. Первым среди них хочу назвать Задорожного Олега Сергеевича. Высокопрофессиональный специалист, всего себя отдающий работе и служению науке. Исполнительный, инициативный. В моё отсутствие очень часто исполняет обязанности заведующего отделением. Как в любом хорошем и толковом подразделении наиболее активными являются наиболее молодые сотрудники. Несмотря на молодость - это единственное достоинство, которое улетучивается с годами - они являются достаточно квалифицированными людьми, которые осваивают не только врачебную специальность, но и научную деятельность. В первую очередь это Насинник Илья Олегович, Кустрин Тарас Богданович и Невская Алла Александровна. Они не только успешно лечат пациентов, но и работают над своими кандидатскими диссертациями.

Среди медсестер хочу отметить старшую медсестру Чернявскую Лидию Александровну, её коллег по работе - Дученко Елену Валерьевну, Науменко Анну Александровну, Мутавчи Марию Ивановну.

Наше отделение, наверное, одно из самых активных и мобильных подразделений клиники, поскольку каждый месяц мы совершаем одну, а то и две поездки, в основном, в Севастополь и в Ровно. В Институте исповедуется принцип: болезнь легче предупредить, чем лечить. Поэтому периодически выезжаем для профилактических осмотров населения в те районы Одесской области, в которых отсутствует врач-офтальмолог. В таких профосмотрах за два дня мы консультируем от 80 человек и больше. Мы стараемся в предельно короткие сроки оказать квалифицированную помощь.

Скажу подробнее о Севастополе. В рамках «Договора о научно-техническом сотрудничестве», заключенного между Филатовским инсти- тутом и Севастопольской городской больницей № 1 имени Н. И. Пирогова, мы один раз в месяц проводим консультации или оперируем в отделении офтальмологии. Отделение возглавляет Горшкова Римма Алексеевна, канд. мед. наук, также ученица Н. В. Пасечниковой, директора нашего института. В отделении имеется лазерный аппарат, позволяющий выполнять определенный перечень вмешательств, достаточно простых. Если же пациенту требуется более квалифицированная диагностика или лечение, его направляют в Институт им. В. П. Филатова.

Обязательно добавлю, что в рамках этого договора в Севастополе оперирует и консультирует заведующий катарактальным отделением микрохирургии глаза нашего института, доктор медицинских наук, профессор Дмитриев Сергей Константинович. В тяжелых случаях, которые не по силам офтальмологам Севастополя, им на помощь приходит ведущий специалист Украины по катарактальной микрохирургии С. К. Дмитриев.

Если продолжить разговор о лазерных вмешательствах, следует сказать, что большую работу проводит Кацан Сергей Владимирович, канд. мед. наук. Он занимается проблемой ретинопатии недоношенных. С помощью лазерного излучения С. В. Кацан консультирует и оперирует недоношенных детей на базе Николаевской областной детской больницы, в Херсонской областной детской больнице и в Симферополе. На место привозится специальный лазерный аппарат и с его помощью при анестезиологическом пособии он проводит лазерные операции на сетчатке недоношенных детей, спасая их от полной слепоты в самом раннем возрасте.

Наше отделение проводит работу также в городе Ровно на базе Первой городской больницы. Один раз в месяц там консультирует Задорожный Олег Сергеевич или я.

K сожалению, полноценное зрение вернуть людям удается не всегда, но то, что тысячам пациентов мы постарались помочь в их беде, это так. Простой пример. Я консультирую в Севастополе уже семь лет. Если, в среднем, у меня на приеме 40 человек и 10 выездов в год, то получается, что несколько тысяч человек я проконсультировал, а несколько сотен - уже прооперировал.

Радует другое. Шесть-семь лет назад на наши консультации приходили только жители городагероя Севастополя. Но потом в Севастополь стали приезжать из Симферополя, Евпатории, Ялты, Судака, Алушты, Феодосии... Значит, люди поверили нам, значит, мы им действительно помогли в беде. Кстати, такая же картина сейчас и в Ровно, куда присылают людей из Луцка, Тернополя, Ковеля. Им проще добраться до города Ровно, чем приехать в Одессу. 
Должен сказать потенциальным пациентам, что самое главное - вовремя обращаться к врачу, когда возникают какие-либо подозрения по поводу своего зрения, потому что любое заболевание легче предотвратить, чем потом лечить, и чем раньше заболевание выявлено, тем лучше результат лечения.

3. Быть военным моряком хорошо, а врачомофтальмологом лучше. Монолог третий, завершающий

С канд. мед. наук Олегом Сергеевичем Задорожным мне довелось общаться неоднократно. Смею вас заверить, если разговорится - интереснейший собеседник. Вот что он поведал о себе и о своей работе в отделении лазерной микрохирургии глаза клиники Института им. академика В. П. Филатова.

В нашей семье никто не связан с медициной, за исключением двоюродного брата, который работает врачом. Отец у меня военный моряк, и хотя родился я в Днепропетровске, помотались мы по разным городам, поскольку место службы не выбирают, а служат там, куда пошлют. Запомнились города Севастополь, Киев и, конечно, Одесса. Здесь я учился, здесь делал выбор своей дальнейшей судьбы. Можно было пойти по стопам отца, мечтавшего, чтобы сын продолжил его дело. Я уважаю и очень ценю нелегкий труд людей морской профессии, потому что здесь, в Одессе, где я долго живу, хорошо знают, что такое быть моряком, военным или гражданским. Но душе хотелось иного.

Свой выбор, вполне осознанный, я сделал в пользу медицины, так как убежден, что помогать людям - это самое благородное занятие на свете. Меня всегда привлекала возможность самому участвовать в таком процессе и видеть его положительные результаты. Почему офтальмология? Выбор тоже не случаен. Мне здесь интересно, так как считаю офтальмологию высокотехнологичной специальностью медицины. Я уверен, что это самаясамая технологичная, наиболее прогрессивно и быстро развивающаяся область медицинской науки. Это меня увлекло настолько, что я стал врачомофтальмологом. Рад, что не ошибся!

Люблю все новинки, особенно, если это связано с технологическими прорывами. К примеру, в нашем Институте им. В. П. Филатова разрабатывается несколько очень интересных направлений в офтальмологии. Во-первых, это работа, проводимая совместно с Институтом электросварки им. Е. О. Патона НАН Украины. Речь идет о применении высокочастотной электросварки биологических тканей для хирургии различных структур глаза. Наиболее широко мы сейчас внедряем эту методику в офтальмоонкологической и витреоретинальной хирургии. Этот метод применяется в общей хирургии для больших полостных операций. Имеет массу преимуществ по сравнению с тради- ционными методиками. Поэтому он находит своё применение в офтальмологии.

Второе направление, которое сейчас мы тоже стараемся развивать - это современные лазерные технологии, например, фемтосекундная лазерная хирургия. Фемтосекундное лазерное устройство позволяет проводить хирургическое вмешательство на очень тонком прецизионном уровне. Работа тоже совместная, но с Киевским институтом физики НАН Украины, где организован комплекс по изучению фемтосекундного лазерного излучения. Уже проведен ряд экспериментов по изучению влияния его на структуры глазного дна, получены первые результаты, сейчас мы их обрабатываем и намерены идти дальше.

Это очень многообещающие направления, связанные со смежными специальностями. Известно, что самые неожиданные открытия делаются на стыках наук. Всё это несомненно интересно и должно дать свой результат для клинической офтальмологии. Таким образом, практикующие врачи получат дополнительные возможности помогать пациентам, попавшим в беду по заболеваниям глаза. Разве это не благородная задача?!

Прежде чем рассказать ещё об одной совместной разработке, вынужден вернуться к своей биографии. В 2003 году я закончил Одесский государственный медицинский университет по специальности «лечебное дело» и поступил в интернатуру по специальности «офтальмология». После этого в Институте глазных болезней и тканевой терапии им. В. П. Филатова я работал над кандидатской диссертацией под руководством директора института, моего учителя Н. В. Пасечниковой. В марте 2009 года защитил диссертацию, которая основана на нашей совместной разработке с Киевским институтом металлофизики НАН Украины. Работа посвящена новому диагностическому методу визуализации структур глазного дна в инфракрасном диапазоне излучения. Этот метод применяется сейчас в нашей практике, есть дальнейшие перспективы развития этого направления.

Ныне я - научный сотрудник отдела по изучению влияния лазерного излучения на структуры глаза. Учитывая, что мы - научно-исследовательский институт, нам каждый год приходится выезжать на межобластные, международные конференции с научными докладами и лекциями. В 2011 году научно-практическая конференция офтальмологов Украины с участием иностранных специалистов из 11 стран состоялась в Одессе на базе нашего института, на котором рассматривались актуальные вопросы офтальмологии. В сентябре этого года были в Луганске на межобластной конференции, где выступали с докладами по нашим разработкам и результатам их применения в клинике. 
Как лазерные хирурги выполняем лазерные вмешательства при сахарном диабете, высокой осложненной близорукости, отслойках сетчатки, нарушениях кровообращения в сосудистой системе глаза и при глаукоме. Это основные направления нашей лечебной деятельности.

Могу сказать одно, я ни разу не пожалел о том, что выбрал свою жизненную дорогу врачаофтальмолога. Более благородной работы я не знаю.

На этой мажорной ноте закончилось третье интервью. Три монолога, три разные судьбы, три ха- рактера. А речь, по сути, шла об одном - о смысле жизни каждого из нас. Как тут не вспомнить слова замечательного татарского поэта Мусы Джалиля: «Стоит жить, чтоб в землю врезать след поглубже, позаметней. Чтоб твоё осталось дело, словно дуб тысячелетний».

По-моему, у всех моих собеседников жизнь сложилась «словно песня»; они заняты самой благородной работой - помогают людям, попавшим в беду.

И пусть каждому достанется наша ответная любовь и уважение к ним - людям в белых халатах. 